Article

\title{
Research on Environmental Sustainability of Coal Cities: A Case Study of Yulin, China ${ }^{\dagger}$
}

\author{
Xiaowei Zhai ${ }^{1, *}$, Zhuo Cheng ${ }^{1}$, Keyu $\mathrm{Ai}^{2}$ and Bo Shang ${ }^{1}$ \\ 1 School of Safety and Engineering, Xi'an University of Science and Technology, Xi'an 710054, China; \\ 18220089033@stu.xust.edu.cn (Z.C.); 18220214090@stu.xust.edu.cn (B.S.) \\ 2 School of Management, The University of Sheffield, Sheffield S1 3JD, UK; kai1@sheffield.ac.uk \\ * Correspondence: zhaixw@xust.edu.cn; Tel.: +86-1357-225-2591 \\ $+\quad$ This work is an extended version of the paper in Energy Reports, 6th International Conference on Energy \\ and Environment Research ICEER 2019, Aveiro, Portugal, 22-25 July 2019; pp 15-20.
}

Received: 26 April 2020; Accepted: 12 May 2020; Published: 14 May 2020

check for updates

\begin{abstract}
Coal cities are an essential impetus for economic development and urbanization processes in China. However, a series of environmental issues provoked by resource exploitation cause the environmental sustainability of coal cities to face enormous challenges. Therefore, on the basis of the time series data of Yulin City from 1996 to 2017, this paper explores the nexus between socioeconomic development and industrial "three wastes" emissions by adopting the Tapio decoupling model, the environmental Kuznets curve (EKC) hypothesis, and the vector auto-regressive (VAR) model. The results show that Yulin's economic development remains in an extensive stage and will not decouple from the environmental pollution in a short time. Except for the nexus of industrial solid waste and economic growth, which is an inverted U-shaped, the EKC hypothesis is not valid for industrial wastewater and industrial waste gas. Through the VAR (2) model, the impact of per capita gross domestic product (GDP) on industrial waste emissions is consistent with the results of the EKC hypothesis. Moreover, industrial waste emissions have a positive correlation with the per capita raw coal output, the energy consumption per unit of GDP, and the proportion of secondary industry. Hence, it is necessary to formulate targeted measures from industrial restructuring, industrial chain extension, governance model optimization, and waste comprehensive utilization to realize the environmental sustainability of coal cities.
\end{abstract}

Keywords: coal city; economic development; environmental issue; Tapio decoupling model; EKC hypothesis; VAR model; environmentally sustainable development

\section{Introduction}

Since the Reform and Opening-up in 1979, China has made significant achievements in economic development. After more than three decades of rapid development, China finally overtook Japan to become the world's second-largest economy after the United States in 2010 [1]. In 2018, China's gross domestic product (GDP) reached 90,031 billion yuan, 198 times that of 1979 [2]. However, rapid economic growth is often associated with a large amount of energy consumption. According to the BP Statistical Review of World Energy data [3], the total primary energy consumption of China reached 3273.5 million tons of oil equivalent in 2018 , accounting for $23.6 \%$ of the world's consumption. Among them, coal consumption reached 1906.7 million tons of oil equivalent, accounting for half of the world's total coal consumption. To alleviate the growing pressure on energy demand, the Chinese government has established 118 resource-based cities according to the resources available in various regions, 63 of which are coal cities [4]. The energy endowment of "rich coal, poor oil, and less gas" determines the critical position of coal resources in China's energy industry, and coal cities have naturally 
become a vital driving force for China's economic development and urbanization [5]. However, the disadvantages of coal cities have gradually emerged with the continuous development of coal resources, such as inefficient utilization of resources, single industry structure, lower economic benefit, severe environmental pollution, frequent geological disasters, high unemployment, and conspicuous social contradictions. These all pose enormous challenges to the sustainable development of coal cities, especially the environmental sustainability [6-8].

Yulin City, located in the northwest of Shaanxi Province, is a typical resource-based city. Because all kinds of energy resources are concentrated in one place, the city is called the continuous energy source of China in the 21st century [9]. In 2018, the city's energy industrial output value reached 353 billion yuan. Yulin City is also a typical coal city. In total, $54 \%$ of the city's area contains coal, with proven reserves of 146 billion tons, accounting for $8.76 \%$ of the national reserves [10]. Since the National Development and Reform Commission announced to establish a state-level energy chemical industry base in Yulin [11], fossil energy has been developed and utilized massively, especially coal mining. As a result, the economy has developed rapidly, material living standards have gradually improved, and economic modernization has made significant achievements [12]. However, like other coal cities, the massive development and utilization of coal also poses a severe test for the ecological environment of Yulin. Liu [13] analyzed 38 soil samples of Yulin through the positive matrix factorization (PMF) model and found that activities related to coal mining were the primary source of heavy metals in soil $(52.5 \%)$, followed by industrial production (22.0\%). Through further research, it was found that excessive coal mining will lead to increasing ecological risks. Zhou [14] analyzed 19 surface water samples and found that coal processing and burning were the principal reasons for the increase of potentially toxic metals in water. Dong [15] also believes that coal mining-related activities are the reason for water pollution in Yulin. Depending on the analysis results of the PMF model, Lei [16] found that the greatest contribution to $\mathrm{PM}_{2.5}$ is the combustion of coal $(58.7 \%)$, while traffic emissions accounted for only $11.7 \%$. It is crucial to conduct environmental sustainability research for coal cities, like Yulin City, to achieve harmonious development of economic growth and environmental protection. Moreover, it lays a foundation for follow-up research on the comprehensive sustainable development of coal cities.

The environmental Kuznets curve (EKC) hypothesis and the decoupling model are essential methods for studying environmentally sustainable development. The EKC hypothesis was originated from Kuznets [17]. When studying the per capita income and income inequality, Kuznets found that the income gap increases first and then decreases with the increase of per capita income. Grossman [18] found that the concentrations of sulfur dioxide and soot in the atmosphere have an inverted U-shaped relationship with income in subsequent studies. In 1995, Arrow [19] proposed the hypothesis that economic growth and environmental pollution have an inverted U-shaped relationship, called the EKC hypothesis. The EKC hypothesis advocates that, at the initial stage of economic development, in order to maintain the rapid development of the economy, an extensive development pattern is selected, which results in environment degradation. When the economy has developed to a certain extent, per capita income has increased significantly, and material needs have been satisfied. The public began to focus attention on the environmental quality. The development pattern gradually became more intensive and the environmental quality was improved.

The early research of the EKC hypothesis focused on the existence test. List [20] investigated the relationship between per capita income and sulfur dioxide and nitrogen oxide emissions in each state of the United States from 1929 to 1994 and found that when income rose to a critical level, sulfur dioxide and nitrogen oxide emissions were negatively correlated with per capita income. The results show that emissions and economic growth in each state follow an inverted U-shaped path, which demonstrates the existence of the EKC hypothesis. Liu [21] also found the existence of an inverted U-shaped curve in studying the relationship between environmental monitoring data and per capita GDP in Shenzhen from 1989 to 2003. Katircioğlu [22], Bimonte [23], and Sinha [24] have also obtained similar conclusions. On the other hand, some studies found that the EKC hypothesis does not exist or has other shapes. 
For instance, Lin [25] tried to test the effectiveness of the EKC in Africa by establishing a non-linear relationship between economic growth and $\mathrm{CO}_{2}$ emissions. On the whole, the results show that economic development driven by either agriculture or industry will not produce the expected results. In addition, Fujii [26] investigated the $\mathrm{CO}_{2}$ emissions and economic growth of different industries in the Organization for Economic Co-operation and Development (OECD) countries from 1970 to 2005, and the results showed that $\mathrm{CO}_{2}$ emissions of different industries are not an inverted U-shape, but an $\mathrm{N}$-shape. It has also found that the economic growth of the construction and steel industries will lead to a continuous increase in $\mathrm{CO}_{2}$ emissions.

As the EKC hypothesis is gradually studied in depth, econometric methods are used and attempts are made to explain the EKC hypothesis in different countries and regions. Zhao [27] studied the relationship between economic development and environmental pollution using the autoregressive distributed lag (ARDL) model. The results show that, after adding the control variable, the $\mathrm{PM}_{2.5}$ concentration and per capita GDP show an inverted U-shaped relationship. On the basis of the traditional EKC model, He [28] used the Stochastic Impacts by Regression on Population, Affluence, and Technology model (STRPAT) to quantitatively study the $\mathrm{PM}_{2.5}$ and $\mathrm{NO}_{2}$ content in 10 cities in the Yangtze River Basin. The study confirmed the existence of the inverted U-shaped curve. In addition, it also found that the urban form could effectively relieve environmental pressure. Hashmi [29] used the time series data of Pakistan from 1971 to 2014 and the ARDL model to establish a theoretical model based on $\mathrm{CO}_{2}$ emissions and economic income, energy consumption, trade openness, and service sector level. The theoretical model shows that the EKC hypothesis exists in Pakistan. There are many similar studies, such as Urban [30] for the Nordic countries, Pata [31] for Turkey, and Pao [32] for G20.

Two points should be emphasized in the EKC hypothesis study. Firstly, it is difficult to form an extended EKC model that applies to all countries or regions because different countries or regions have different industrial structures, technological levels, environmental regulations, development levels, and stages $[33,34]$. Secondly, the EKC hypothesis describes the long-run relationship between economic growth and environmental pressure, and it is not easy to verify in a shorter period, especially for a specific year.

The concept of "decoupling" originated in the field of physics, which means that the response relationship between two physical quantities disappeared. In 1996, Garter [35] raised the issue of decoupling of economic development and environmental pollution, and introduced the decoupling theory into the environmental field for the first time. Since then, research on "decoupling" has not stopped in this field. In 2002, when the OECD [36] studied the correlation between economic growth and environmental pollution, a simple model was established to demonstrate the degree of decoupling between the two, known as the OECD decoupling model. This model reflects the degree of decoupling through the changes between environmental pollutants and their driving forces, such as carbon emissions and GDP growth. When the growth rate of environmental pollutants is below the growth rate of driving forces, they are in decoupling state. Moreover, Vehmas [37] constructed a more complete framework for decoupling. However, the relationship between economic growth and environmental pollution is complicated, and it is not comprehensive to describe this complex nexus by relative decoupling and absolute decoupling. Therefore, Tapio [38] expanded Vehmas's research and proposed a theoretical model with eight kinds of decoupling types based on the decoupling elastic index, that is, Tapio decoupling model.

At present, many research achievements have been made based on decoupling theory in the environmental field. Freitas [39] used the OECD decoupling model to analyze the relationship between energy consumption, $\mathrm{CO}_{2}$ emissions, and economic activity in Brazil from 2004 to 2009. The study noted that there was an absolute decoupling between these variables in 2009, while several relative decouplings occurred in other years. Wang [40] used the Tapio decoupling model to study the decoupling state between economic growth and carbon emissions in China's transportation sector. The results prove that there has been a stable decoupling in eastern China. Gou [41] found that the province's dependence on fossil energy has gone through an inverted U-shaped process, and the 
economic growth pattern has gradually moved closer to being environmentally friendly from the Tapio decoupling study of China's provincial panel data from 2004 to 2015. Compared with the OECD decoupling model, the Tapio decoupling model is not limited in the choice of the base period [42]. At the same time, the nature of the Tapio decoupling model determines that it will not be disturbed by the dimensions of data in the empirical analysis [43]. The advantage of the Tapio decoupling model is that it can measure the degree of decoupling of economic growth and environmental pollution by establishing different economic and environmental indicators. The disadvantage is that the selected economic indicators are usually established based on a clear year [44], which makes it impossible to judge long-term trends.

To provide a theoretical basis for the environmental sustainability of coal cities, this paper uses the Tapio model and the EKC hypothesis to explore the evolution of economic development and environmental pollution in Yulin City. Moreover, the vector auto-regressive (VAR) model is used to analyze the impact of socioeconomic factors on environmental pollution.

Compared with previous work, the contribution of this paper can be summarized in the following aspects. First of all, as a typical representative of coal cities, the nexus of economic development and environmental pollution of Yulin can be seen as an epitome of coal cities in China. On the basis of the results, some targeted suggestions can be made. Secondly, according to the development characteristics of coal cities, the per capita industrial "three wastes" emissions (solid waste, wastewater, waste gas) are taken as indicators of environmental pollution, and the per capita GDP is taken as the economic indicator. It is possible to systematically study the dynamic evolution of the relationship between economic growth and environmental pollution from the short term to the long term based on the Tapio decoupling model and the EKC hypothesis. Third, the nexus between environmental pollution and socioeconomic factors can be analyzed by establishing the VAR model. That is to say, the impact of economic income, energy development and utilization, industrial structure, and technology advance on the per capita industrial "three wastes" emissions can be obtained through the impulse response and variance decomposition.

\section{Data and Methods}

\subsection{Data}

Taking Yulin City as an example, this paper discusses the relationship between socioeconomic factors (economic development, energy development and utilization, industry structure change, technological advance) and environmental pollution, in order to provide a theoretical basis for environmentally sustainable development of coal cities. Among them, economic development is represented by real per capita GDP (PGDP) (in constant 1996 RMB yuan). Considering that energy development in Yulin is dominated by coal, using per capita raw coal output (PCO) represents energy development. Energy utilization is expressed by energy consumption per unit of GDP $(\mathrm{ECP})$, representing energy efficiency. The lower the ECP, the higher the energy utilization efficiency. The industrial structure is determined by the proportion of value-added of the secondary industry in GDP (PSI). Technology advancement is expressed by the proportion of technology investment in financial expenditure (PTI). As a state-level energy chemical industrial base, Yulin has high industrial "three wastes" emissions. Therefore, environmental pollution indicators are expressed by per capita industrial solid waste production (Psolid), per capita industrial wastewater discharge (Pwater), and per capita industrial waste gas emissions (Pgas), respectively. All data are derived from the Statistical Yearbook of Yulin [45] and the Shaanxi Statistical Yearbook [46]. As the statistical results of industrial wastes emissions in 2018 remain unpublished, the period of this study is from 1996 to 2017. The detailed description of each variable is presented in Table 1. 
Table 1. A detailed description of the variables.

\begin{tabular}{cccccc}
\hline Variables & Unit & Min. & Max. & Mean & Sd $^{\mathbf{1}}$ \\
\hline Psolid & Ton/person & 0.069 & 7.297 & 2.828 & 2.334 \\
Pwater & Ton/person & 2.104 & 35.558 & 9.022 & 8.343 \\
Pgas & $\mathrm{m}^{3} /$ person & 2739.376 & $169,305.497$ & $55,570.956$ & $57,475.027$ \\
PGDP & yuan & 1880.302 & $21,932.265$ & 9013.954 & 6975.109 \\
PCO & Ton/person & 2.010 & 103.927 & 43.653 & 38.324 \\
ECP & Tsce $2 / 10^{4}$ yuan & 1.547 & 8.830 & 3.033 & 2.145 \\
PSI & $\%$ & 30.305 & 72.233 & 57.450 & 11.879 \\
PTI & $\%$ & 0.376 & 1.424 & 0.888 & 0.368 \\
\hline
\end{tabular}

Note: ${ }^{1}$ Sd indicate standard deviation. ${ }^{2}$ Tsce indicate ton standard coal equivalent. PGDP, per capita gross domestic product; PCO, per capita raw coal output; ECP, energy consumption per unit of GDP; PSI, proportion of value-added of the secondary industry in GDP; PTI, proportion of technology investment in financial expenditure.

\subsection{Tapio Decoupling Model}

Compared with other decoupling models, the Tapio decoupling model uses the value of the decoupling elastic index to reflect the decoupling state between economic dynamism and environmental pressure, which improves the objectivity and accuracy of decoupling measurement [47]. Therefore, this paper uses the Tapio decoupling model to study the decoupling state between per capita industrial "three wastes" emissions and per capita GDP (in constant 1996 RMB yuan) from 1996 to 2017. The calculation formula of the Tapio decoupling elastic index is shown in Equation (1):

$$
\mathrm{e}_{\mathrm{t}}=\left(\frac{\Delta \mathrm{EP}_{\mathrm{t}}}{\mathrm{EP}_{\mathrm{t}-1}}\right) /\left(\frac{\Delta \mathrm{PGDP}_{\mathrm{t}}}{\mathrm{PGDP}_{\mathrm{t}-1}}\right)=\left(\frac{\mathrm{EP}_{\mathrm{i}}-\mathrm{EP}_{\mathrm{t}-1}}{\mathrm{EP}_{\mathrm{t}-1}}\right) /\left(\frac{\mathrm{PGDP}_{\mathrm{t}}-\mathrm{PGDP}_{\mathrm{t}-1}}{\mathrm{PGDP}_{\mathrm{t}-1}}\right)
$$

where $\mathrm{e}_{\mathrm{t}}$ denotes decoupling elastic index; $\mathrm{EP}_{\mathrm{t}}$ represents the emissions of industrial "three wastes", including per capita industrial solid waste production (Psolid), per capita industrial wastewater emission (Pwater), and per capita industrial waste gas emission (Pg); $\mathrm{PGDP}_{\mathrm{t}}$ is the per capita GDP; $\Delta \mathrm{EP}_{\mathrm{t}}$ represents the change in industrial "three wastes" emissions; $\triangle \mathrm{PGDP}_{\mathrm{t}}$ represents the change in per capita GDP; and $t=1997,1998, \ldots, 2017$.

According to the calculation results, the Tapio decoupling theory divides the decoupling states into eight types, as is illustrated in Figure 1. Different types reflect the diverse development patterns [48]. If the per capita income increases $(\triangle \mathrm{PGDP}>0$ ), there are four kinds of decoupling states. Among them, expansive negative decoupling represents an extensive expansion development. Expansive coupling indicates inefficient expansion development. Weak decoupling represents intensive expansion. Strong decoupling represents environmentally friendly development, which is the ideal state between the economy and environment.

When the per capita income decreases $(\triangle \mathrm{PGDP}<0)$, there are also four kinds of decoupling states. Strong negative decoupling indicates an extensive, but sluggish development. Weak negative decoupling represents a sluggish development. Recessive coupling indicates an inefficient and sluggish development. Recessive decoupling means an intensive, but recessive development. 


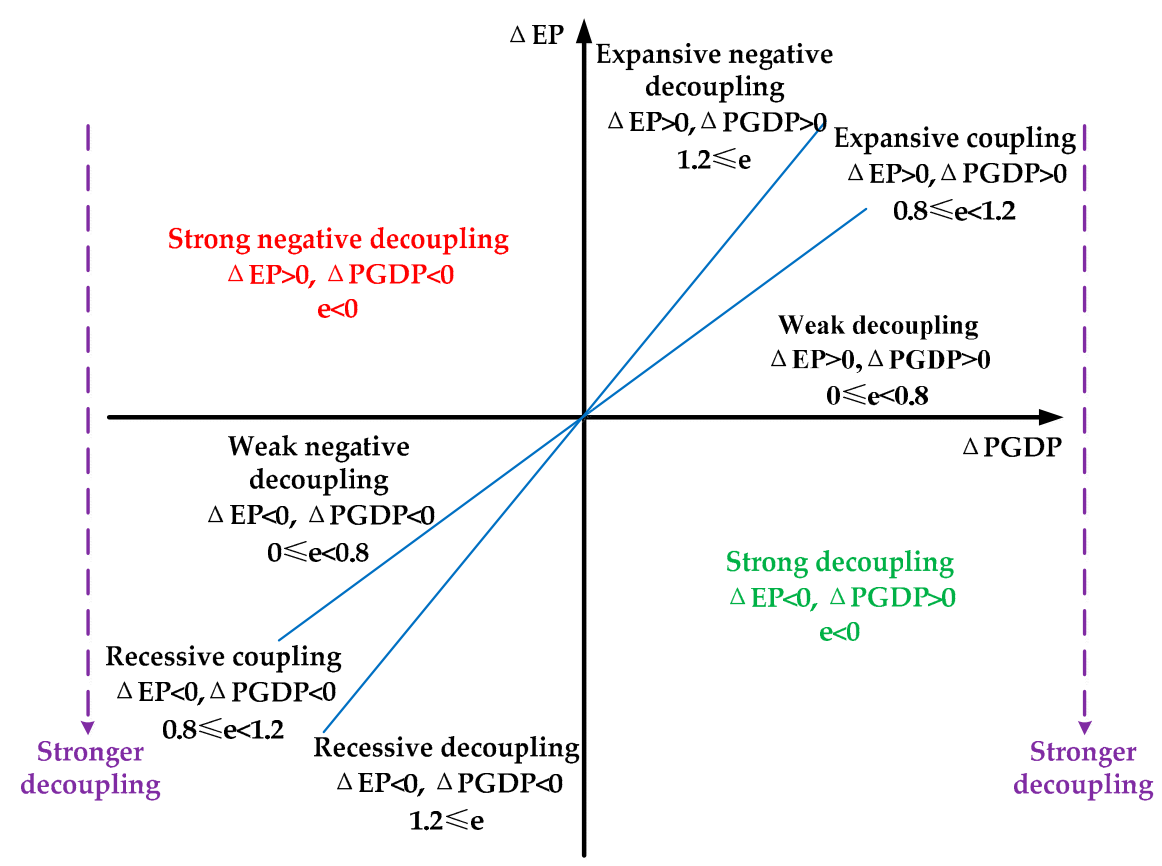

Figure 1. Judgments matrix of decoupling based on the Tapio decoupling model. PGDP, per capita gross domestic product. $\triangle \mathrm{EP}$ represents the change in industrial "three wastes" emissions. $\triangle \mathrm{PGDP}$ represents the change in per capita GDP.

\subsection{EKC Hypothesis}

The EKC hypothesis advocates that, with the increase of economy, the degree of environmental pollution will show an inverted U-shaped change. The traditional EKC model was established with per capita GDP as the explanatory variable and per capita industrial waste emissions (solid waste, wastewater, waste gas) as the explained variable. Combined with the empirical literature of environmental economics $[49,50]$, the above variables are in their natural logarithms. The model can be expressed as follows:

$$
\begin{gathered}
\operatorname{lnPsolid}_{t}=\alpha_{0}+\beta_{1} \operatorname{lnPGDP}_{\mathrm{t}}+\beta_{2} \ln ^{2} \mathrm{PGDP}_{\mathrm{t}}+\mathrm{u}_{\mathrm{t}} \\
\operatorname{lnPwater}_{\mathrm{t}}=\alpha_{0}+\beta_{1} \operatorname{lnPGDP}_{\mathrm{t}}+\beta_{2} \ln ^{2} \mathrm{PGDP}_{\mathrm{t}}+\mathrm{u}_{\mathrm{t}} \\
\operatorname{lnPgas}_{\mathrm{t}}=\alpha_{0}+\beta_{1} \operatorname{lnPGDP}_{\mathrm{t}}+\beta_{2} \ln ^{2} \mathrm{PGDP}_{\mathrm{t}}+\mathrm{u}_{\mathrm{t}}
\end{gathered}
$$

where Psolid represents per capita industrial solid waste production, Pwater represents per capita industrial wastewater discharge, Pgas represents per capita industrial waste gas emissions, PGDP stands for per capita GDP, $\alpha_{0}$ indicates the intercept, $u_{t}$ is a random error component, and $\beta_{1}$ and $\beta_{2}$ are the undetermined coefficients.

The EKC hypothesis is tenable if $\beta_{1}$ is positive and $\beta_{2}$ is negative. In other words, economic growth will lead to an increase in industrial waste emissions during the initial development period. Nevertheless, in the long run, when the economy develops to a certain level, that is, the inflection points of EKC $\left(-\beta_{1} / 2 \beta_{2}\right)$, more attention is given to environmental issues, and industrial waste emissions are gradually reduced.

\subsection{VAR Model}

The VAR model is an unstructured model based on the statistical property of the data [51]. The model is constructed by taking each endogenous variable as the lagging value of all endogenous variables in the system. Therefore, the univariate autoregressive model is extended to the vector autoregressive model, which is composed of multivariate time series variables [52]. 
To further analyze the impact of socioeconomic development on environmental pollution in Yulin City, this paper establishes VAR models by adopting socioeconomic factors and environmental pollutants. Among them, the socioeconomic factors include PGDP, PCO, ECP, PSI, and PTI. The environmental pollutants include Psolid, Pwater, and Pgas. All the above variables are in their natural logarithms. The VAR model is as follows:

$$
\mathrm{Y}_{\mathrm{t}}=\mathrm{c}+\sum_{\mathrm{i}=1}^{\mathrm{p}} \delta_{\mathrm{i}} \mathrm{Y}_{\mathrm{t}-\mathrm{i}}+\xi_{\mathrm{t}}
$$

where $Y_{t}$ is a column vector of $n$-dimensional endogenous variables, $Y_{t-i}$ is the $i$-order lag vector of the $\mathrm{Y}_{\mathrm{t}}, \mathrm{C}$ is the intercept vector, $\delta_{\mathrm{i}}$ is an $\mathrm{n} \times \mathrm{n}$ dimensional parameter matrix, $\mathrm{P}$ is the lag order, and $\xi_{\mathrm{t}}$ is n-dimensional random disturbance term.

\section{Results and Discussion}

\subsection{Decoupling Between Economy and Environment}

To reveal the pattern of economic development of Yulin City in the past two decades, this paper uses the Tapio decoupling model to analyze the decoupling state of economic growth and environmental deterioration from 1996 to 2017. According to the calculation formula of the Tapio decoupling model, the decoupling state in 1996 needs to be based on the relevant data of 1995. Nevertheless, as the data before 1996 were not published, the decoupling state in 1996 cannot be calculated. The specific calculation results are shown in Table 2.

Table 2. The decoupling states in Yulin City during 1997-2017.

\begin{tabular}{|c|c|c|c|c|c|c|c|c|c|c|c|}
\hline \multirow{2}{*}{ Year } & \multicolumn{3}{|c|}{ Pollutants } & \multirow{2}{*}{ Year } & \multicolumn{3}{|c|}{ Pollutants } & \multirow{2}{*}{ Year } & \multicolumn{3}{|c|}{ Pollutants } \\
\hline & Psolid & Pwater & Pgas & & Psolid & Pwater & Pgas & & Psolid & Pwater & Pgas \\
\hline 1997 & SND & SND & SND & 2004 & END & END & END & 2011 & SD & WD & END \\
\hline 1998 & END & END & END & 2005 & END & WD & END & 2012 & END & SD & WD \\
\hline 1999 & SND & RD & $\mathrm{RC}$ & 2006 & EC & EC & WD & 2013 & WD & SD & END \\
\hline 2000 & END & WD & WD & 2007 & END & END & WD & 2014 & END & END & END \\
\hline 2001 & SD & WD & END & 2008 & SD & SD & END & 2015 & END & END & END \\
\hline 2002 & END & SD & END & 2009 & END & END & END & 2016 & END & SD & END \\
\hline 2003 & EC & WD & WD & 2010 & WD & WD & END & 2017 & SD & END & SD \\
\hline
\end{tabular}

Note: SND stands for strong negative decoupling; RC stands for recessive coupling; RD stands for recessive decoupling; END stands for expansive negative decoupling; EC stands for expansive coupling; WD stands for weak decoupling; SD stands for strong decoupling.

As shown in Table 2, from the perspective that the decoupling state changes with the year, the decoupling state between economic growth and environmental degradation alternately appeared from 1997 to 2017, but it still dominated by the expansive negative decoupling. For the production of per capita industrial solid waste, the strong negative decoupling and expansive negative decoupling, which represent extensive development, have occurred 13 times. The strong decoupling, which represents environmentally friendly development, has only appeared four times, accounting for $19.0 \%$. For the discharge of per capita industrial wastewater, extensive development has occurred eight times. The strong decoupling has only appeared five times, accounting for $23.8 \%$. For the emissions of per capita industrial waste gas, strong negative decoupling and expansive negative decoupling have occurred 14 times, while strong decoupling has only appeared once, accounting for $4.8 \%$.

The way of economic growth in Yulin has mainly focused on extensive development in the past two decades, which will cause extremely damage to the environment. Moreover, from the perspective of pollutant categories, economic development is more closely coupled with industrial solid waste production and industrial waste gas emissions. As a typical coal city, Yulin is mainly supported by heavily polluting industries such as energy and chemical industry. The enterprises producing 
industrial solid waste mainly come from the coal processing industry, chemical industry, and extractive industry [53]. The most significant output of industrial solid waste is coal gangue, followed by fly ash and slag. Abundant coal resources are used in coke-making and thermal power generation, which is bound to result in a large volume of industrial waste gas emissions.

Since 2000, per capita GDP in Yulin has increased yearly $(\triangle P G D P>0)$. In theory, there are merely four kinds of decoupling states. Moreover, the value of the decoupling elastic index can reflect the degree of decoupling between economic growth and environmental pollution. In other words, since 2000, the larger the decoupling elastic index, the more prominent the economic development at the expense of environmental quality. Therefore, in order to further illustrate the process of decoupling between environmental degradation and economic development, this paper divides the period into three stages according to "The Five-Year Plan" [54], which are 2001-2005 (the 10th Five-Year Plan), 2006-2010 (the 11th Five-Year Plan), 2011-2015 (the 12th Five-Year Plan), and averages the decoupling elastic index of each stage. The results are presented in Table 3.

Table 3. The average value of the decoupling elastic index in each stage.

\begin{tabular}{cccc}
\hline Pollutants & 2001-2005 & $\begin{array}{c}\text { Stage } \\
\text { 2006-2010 }\end{array}$ & $\mathbf{2 0 1 1 - 2 0 1 5}$ \\
\hline Psolid & 3.055 & 0.608 & 2.136 \\
Pwater & 0.876 & 2.971 & 1.419 \\
Pgas & 1.806 & 1.539 & 1.749 \\
\hline
\end{tabular}

As shown in Table 3, except for Psolid showing weak decoupling in the 11th Five-Year Plan and Pwater showing expansive decoupling in the 12th Five-Year Plan, industrial "three wastes" emissions are expansive negative decoupling in the remaining stages. This further confirms the dominant position of the extensive development pattern in the economic development of Yulin City.

From the changing trend of the decoupling elastic index, industrial solid waste is U-shaped, industrial wastewater is inverted U-shaped, and industrial waste gas is weakly U-shaped. This also verifies the tight connections between economic development and environmental degradation. Even for industrial wastewater, inverted U-shaped, the decoupling elastic index is consistently higher than 1.2. This shows that economic growth that is over-dependent on the resources development and utilization will not decouple from the environmental pollution in a short period.

\subsection{EKC Hypothesis in Yulin}

The EKC hypothesis is a theoretical model for testing the long-term relationship between economic growth and environmental pollution, and the variables usually adopt time series data. Before analyzing the time series data, the stationarity of the data must be tested to avoid spurious regression. Therefore, this paper uses augmented Dickey Fuller (ADF) [55] and Phillips-Perron (PP) [56] to perform unit root tests on $\ln P$ solid, $\ln P w a t e r, \ln P g a s, \ln P G D P$, and $\ln ^{2} \mathrm{PGDP}$ and their first-order difference sequences. The results of the unit root tests are shown in Table 4.

Table 4. The results of unit root tests.

\begin{tabular}{ccccc}
\hline \multirow{2}{*}{ Variables } & \multicolumn{2}{c}{ Level } & \multicolumn{2}{c}{ 1st Difference } \\
& ADF & PP & ADF & PP \\
\hline lnPsolid & $-3.964^{* *}$ & $-4.053^{* *}$ & $-5.108^{* * *}$ & $-5.235^{* * *}$ \\
lnPwater & -3.496 & -2.598 & $-6.499^{* * *}$ & $-6.499^{* * *}$ \\
lnPgas & -1.199 & -1.292 & $-4.766^{* * *}$ & $-4.773^{* * *}$ \\
lnPGDP & $-5.279^{* * *}$ & 5.142 & $-3.818^{* * *}$ & $-3.836^{* * *}$ \\
$\ln ^{2}$ PGDP & $-4.216^{* * *}$ & -2.254 & $-3.550^{* * *}$ & $-3.557^{* *}$ \\
\hline
\end{tabular}

Notes: ${ }^{* * *}$ indicated $1 \%$ significance levels; ${ }^{* *}$ indicated $5 \%$ significance levels. ADF, augmented Dickey Fuller; PP, Phillips-Perron. 
As shown in Table 4, except that the lnPsolid is I(0), all variables reject the null hypothesis, that is, non-stationarity. After the first-order difference of all variables, the results of the ADF test and the PP test reject the null hypothesis, meaning they are integrated at I(1).

To ensure that the calculation results can authentically reflect the relationship between economic growth and environmental pollution in Yulin, this paper uses Johansen cointegration [57] to test the long-term equilibrium relationship of the variables. The results are shown in Table A1 (Appendix A). From Table A1, there is a long-term equilibrium relationship between the variables of each model. Therefore, the three EKC models are fit based on the least square method, and the results are shown in Table 5.

Table 5. The fitting results of the environmental Kuznets curve (EKC) models.

\begin{tabular}{ccccc}
\hline Pollutants & $\boldsymbol{\beta 1}$ & $\boldsymbol{\beta 2}$ & $\boldsymbol{\alpha 0}$ & $\mathbf{R 2}$ \\
\hline Psolid & 9.057 & -0.443 & -44.542 & 0.875 \\
Pwater & -3.406 & 0.251 & 12.202 & 0.926 \\
Pgas & 3.165 & -0.091 & -10.520 & 0.992 \\
\hline
\end{tabular}

According to Table 5, the nexus between economic growth and per capita industrial solid waste production is inverted U-shaped, which is in line with the EKC hypothesis. The inflection point is 10.232, and the corresponding per capita GDP is 27,511 yuan (in constant 1996 RMB yuan). In 2017, the per capita GDP of Yulin was 21,932 yuan (in constant 1996 RMB yuan). On the basis of the GDP growth rate (8\%) in 2017 [58], it is expected to reach the inflection point in 2021.

There is a U-shaped relationship between per capita industrial wastewater discharge and economic growth $\left(\beta_{1}<0, \beta_{2}>0\right)$, meaning the EKC hypothesis is invalid. If calculated by the inflection point calculation formula, the per capita GDP corresponding to the inflection point is 884 yuan (in constant 1996 RMB yuan), while the per capita GDP in 1996 is 1907 yuan. This indicates that there will be a positive correlation between economic growth and per capita industrial wastewater discharge in the coming period.

The relationship between per capita industrial waste gas emissions and economic growth represents an inverted U-shape, which theoretically conforms to the EKC hypothesis. However, the per capita GDP corresponding to the inflection point is 3.56 million yuan (in constant 1996 RMB yuan). Such a high economic income is almost impossible to achieve. This situation has also occurred in other studies. When Shi [59] studied the $\mathrm{CO}_{2}$ emissions of 93 countries, he found that the inflection point of per capita income was also very high, ranging from 4.6 million to 7 million U.S. dollars. Holtz-Eakin [60] obtained a higher inflection point in the study of $\mathrm{CO}_{2}$ emissions and economic growth, reaching 8 million U.S. dollars. For the practical situation, however, there does not exist the environmental Kuznets curve of per capita industrial waste gas emissions in Yulin City.

\subsection{The Impact of Socio-Economic Factors on Environmental Pollution}

\subsubsection{VAR Model Establishment}

Coal cities play an indispensable role in China's economic development and urbanization processes. However, the over-exploitation and utilization of resources has also caused severe damage to the environment. Different from other cities, the economic development of coal cities mainly focuses on energy development. A single industrial structure, inefficient energy utilization, and massive industrial "three wastes" emissions are also the distinctive features of coal cities. Hence, when analyzing the influencing factors of environmental pollution, the indicators should be selected according to the characteristics of coal cities.

The VAR model can scientifically and effectively analyze the impact of socioeconomic factors on environmental pollution in Yulin City. Before establishing the VAR model, it is imperative to determine the stationarity of the variables. This paper adopts ADF and PP to test the stationarity of each variable. The test results are shown in Table 6. 
Table 6. The results of unit root tests.

\begin{tabular}{ccccc}
\hline Variables & \multicolumn{2}{c}{ Level } & \multicolumn{2}{c}{ 1st Difference } \\
& ADF & PP & ADF & PP \\
\hline lnPsolid & $-3.964^{* *}$ & $-4.053^{* *}$ & $-5.108^{* * *}$ & $-5.235^{* * *}$ \\
lnPwater & -3.496 & -2.598 & $-6.499^{* * *}$ & $-6.499^{* * *}$ \\
lnPgas & -1.199 & -1.292 & $-4.766^{* * *}$ & $-4.773^{* * *}$ \\
lnPGDP & $-5.279^{* * *}$ & 5.142 & $-3.818^{* * *}$ & $-3.836^{* * *}$ \\
lnPCO & -1.936 & -1.936 & $-4.867^{* * *}$ & $-4.043^{* * *}$ \\
lnECP & $-8.923^{* * *}$ & $-3.917^{* * *}$ & $-6.514^{* * *}$ & $-3.432^{* * *}$ \\
lnPSI & $-3.641^{* * *}$ & $-4.443^{* * *}$ & $-9.005^{* * *}$ & $-25.964^{* * *}$ \\
lnPTI & -1.172 & -1.362 & $-5.914^{* * *}$ & $-5.919^{* * *}$ \\
\hline Notes: ${ }^{* * *}$ indicated $1 \%$ significance levels; ${ }^{* *}$ indicated $5 \%$ significance levels.
\end{tabular}

It can be seen from Table 6 that at the level, except for Psolid, ECP, and PSI, the remaining variables all failed to reject the null hypothesis that the series is non-stationary. After first-order difference, all variables reject the null hypothesis at the $1 \%$ significance level, meaning they are integrated at $\mathrm{I}(1)$. Therefore, in the subsequent analysis, we use the differential sequences of these variables for research. Among them, DlnPsolid represents the variation of per capita industrial solid waste production, DlnPwater represents the variation of per capita industrial wastewater discharge, DlnPgas represents the variation of per capita industrial waste gas emissions, DlnPGDP represents the change in per capita GDP, DlnPCO represents the change in per capita raw coal output, DlnECP represents the change in energy consumption per unit of GDP, DlnPSI represents the change in the proportion of the secondary industry, and DlnPTI represents the change in the proportion of technology investment.

In order to make the parameters have a strong explanatory ability, this paper determines the optimal lag order of the VAR models through the five criterions, which are LR (Logistic regression), FPE (Final prediction error criterion), AIC (Akaike info criterion), SC (Schwarz criterion), and HQ (Hannan-Quinn criterion). The results are shown in Table A2 (Appendix A). According to Table A2, the optimal lag order corresponding to the three environmental pollutants is second order.

At the same time, this paper uses Johansen cointegration to test the long-term equilibrium relationship of the socioeconomic factors and industrial "three wastes". The results are shown in Table A3 (Appendix). The test results reject the hypothesis that there is no cointegration relationship among these variables. Therefore, the VAR (2) model for each industrial waste is established, as shown in Appendix B.

By calculating the AR characteristic polynomials of each model, as shown in Figure 2, it is found that the reciprocals of all AR characteristic polynomials are within the unit circle, indicating that the three VAR (2) models are stable.
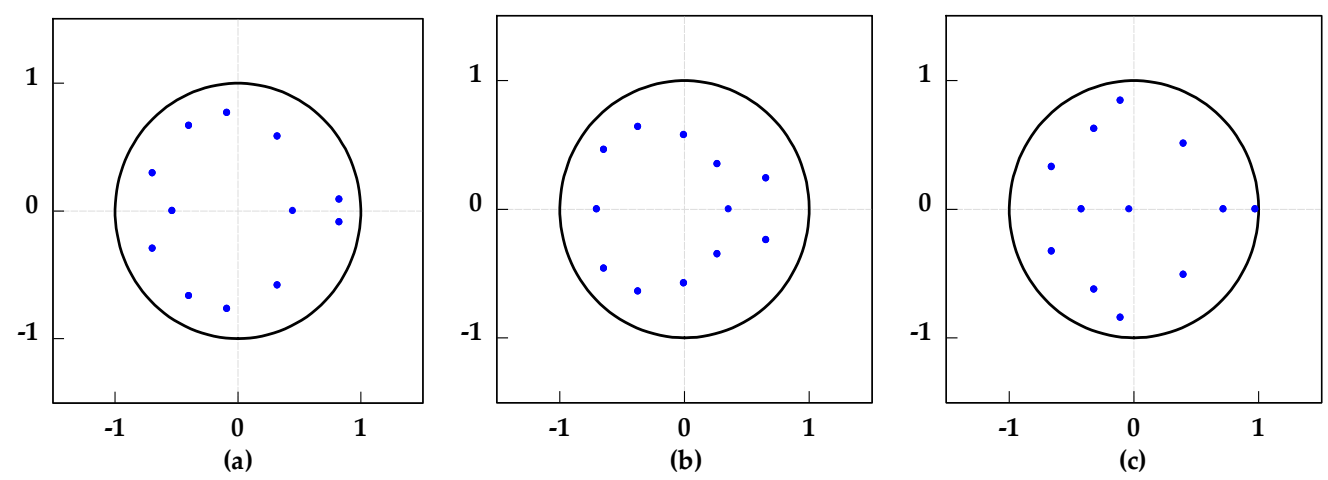

Figure 2. The results of stability test for the vector auto-regressive (VAR) (2) models. (a) The inverse roots of AR characteristic polynomial of the VAR (2) model A1. (b) The inverse roots of AR characteristic polynomial of the VAR (2) model A2. (c) The inverse roots of AR characteristic polynomial of the VAR (2) model A3. 


\subsubsection{The Impulse Response of Environmental Pollution to Socioeconomic Factors}

After applying a standard deviation shock to an endogenous variable, the impulse response function can be used to observe the impact of this variable on the others. Therefore, this paper uses the impulse response function to analyze the impact of socioeconomic factors on environmental pollutants. The specific impulse response function curve is shown in Figure 3.
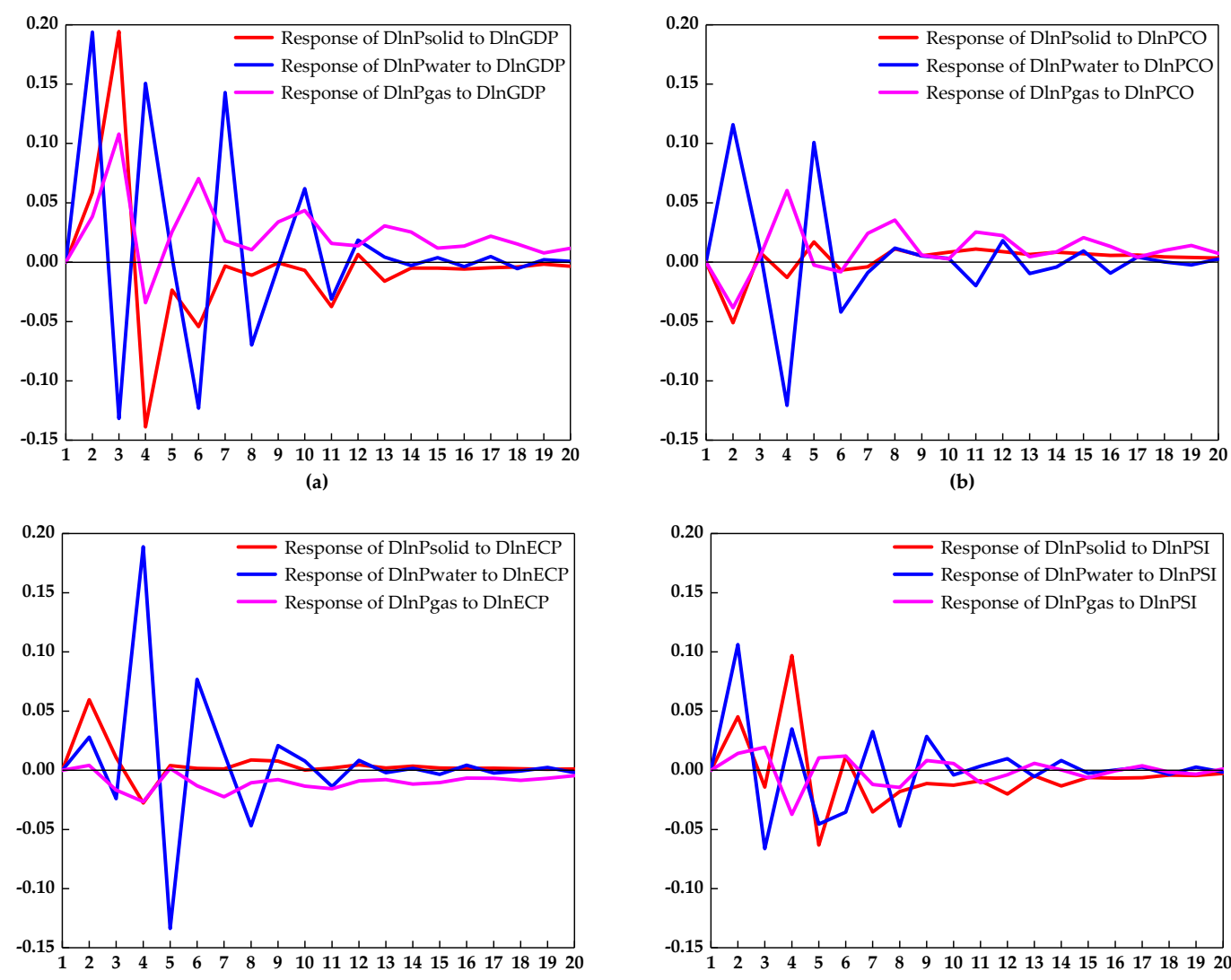

(c)

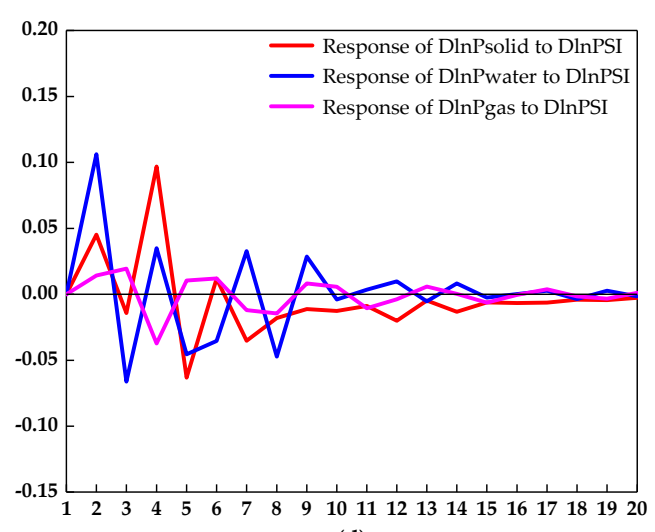

(d)

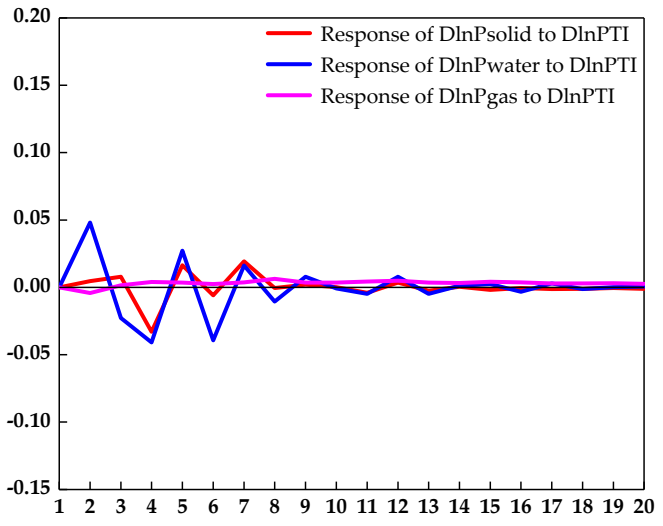

(e)

Figure 3. The impulse response of industrial "three wastes" emissions to socio-economic factors. (a) The response of environmental pollutants to DlnPGDP. (b) The response of environmental pollutants to DlnPCO. (c) The response of environmental pollutants to DlnECP. (d) The response of environmental pollutants to DlnPSI. (e) The response of environmental pollutants to DlnPTI. PCO, per capita raw coal output; ECP, energy consumption per unit of GDP; PSI, proportion of value-added of the secondary industry in GDP; PTI, proportion of technology investment in financial expenditure. 
As shown in Figure 3a, after applying a positive shock to DlnPGDP, DlnPsolid gradually increased and peaked in the third period. The industrial solid waste output will decrease in the subsequent period after reaching the maximum negative response point in the fourth period. This indicates that economic growth will lead to an inverted U-shaped trend in the industrial solid waste output. The result is consistent with the previous analysis of the EKC hypothesis for industrial solid waste. The industrial wastewater discharge increased rapidly under the positive shock of DlnPGDP. Different from the industrial solid waste output, the positive and negative response fluctuations in the amount of industrial wastewater discharge remained after reaching the maximum negative response point in the third period. Overall, however, the positive response is stronger than the negative response. This indicates that economic growth will eventually lead to an increase in industrial wastewater discharge in the long run. This is also consistent with the EKC hypothesis of industrial wastewater discharge. Except for the negative response in the fourth period, the industrial waste gas emissions are in a positive response during the rest of the period. Compared with the other two types of industrial waste, industrial waste gas emissions are less affected by economic growth. However, the overall trend is still increasing. This trend also confirms the conclusion that the inflection point of industrial waste gas is almost impossible to reach.

As shown in Figure 3b, the production of industrial solid waste and the emissions of industrial waste gas will keep increasing slightly after a short period of improvement. The discharge of industrial wastewater fluctuates between the positive and negative responses under the impact of DlnPCO. The raw coal needs to go through washing, transportation, storage, and other processes before it can be put into use. Therefore, the increase of raw coal output in the current period will have a lagging effect on the production of industrial solid waste and the emission of industrial waste gas. In the long run, however, the industrial waste emissions will be promoted by the increase of raw coal output.

As shown in Figure 3c, after giving DlnECP a positive shock, the industrial solid waste production will experience an increase, then a small decrease, and finally stabilized at a zero growth rate. The positive and negative responses appear alternately in industrial wastewater discharge under the influence of DlnECP. From the perspective of response intensity, however, the positive response still dominates. The industrial waste gas emissions are dominated by a tiny negative response, which indicates that variations in energy consumption per unit of GDP will not cause a significant decrease in industrial waste gas emissions. From the above changing process, the increase in energy consumption per unit of GDP, that is, the decrease in energy efficiency, will promote the production of industrial solid waste and the discharge of industrial wastewater. The difference is that the production of industrial solid waste will return to an equilibrium state in a relatively brief time.

As shown in Figure 3d, the industrial solid waste output will increase in an initial period and then decrease after the fourth period. Moreover, the industrial wastewater and the industrial waste gas will fluctuate in positive and negative responses after giving DlnPSI a positive shock. The secondary industry, as the main driving force for economic growth, occupies a high proportion in the economic structure of Yulin. The development of the secondary industry is bound to cause a great deal of industrial "three wastes" emissions. Moreover, the intervention of the government will improve environmental quality, and economic growth will also be inhibited by this intervention. Then, to restore economic growth, the intervention will be weakening and the industrial "three wastes" emissions will rebound. Eventually, the fluctuation of emissions in Figure $3 \mathrm{~d}$ is formed.

As shown in Figure 3e, industrial solid waste output and industrial wastewater discharge will be fluctuating between positive and negative responses after giving DlnPTI a positive shock. Industrial waste gas emissions increase very slightly. Technology investment is mainly used in two aspects. On the one hand, it is to increase the production efficiency for economic income. On the other hand, it is to improve the production process for protecting the environment. Increasing productivity is bound to lead to more industrial "three wastes" emissions. The government will enhance investment in production process improvement to eliminate this adverse effect. From the impulse response curve, 
the fluctuation process of industrial waste emissions reflects the allocation of technology investment between these two aspects.

On the basis of the above analysis, the nexus between economic income and environmental pollutants conforms to the EKC analysis conclusion. In the long run, the increase in per capita raw coal production, energy consumption per unit of GDP, and the proportion of secondary industries will lead to an increase in the industrial "three wastes" emissions. The increasing proportion of technology investment causes fluctuations up and down of industrial "three wastes" emissions.

\subsubsection{The Variance Decomposition of Environmental Pollution}

Variance decomposition is used to analyze the contribution of each structural shock to the change of endogenous variables. It can evaluate the importance of different structural shocks. In this paper, we adopt the variance decomposition to investigate the impact of various socioeconomic factors on the industrial "three wastes" emissions. The variance decomposition curve is shown in Figure 4.

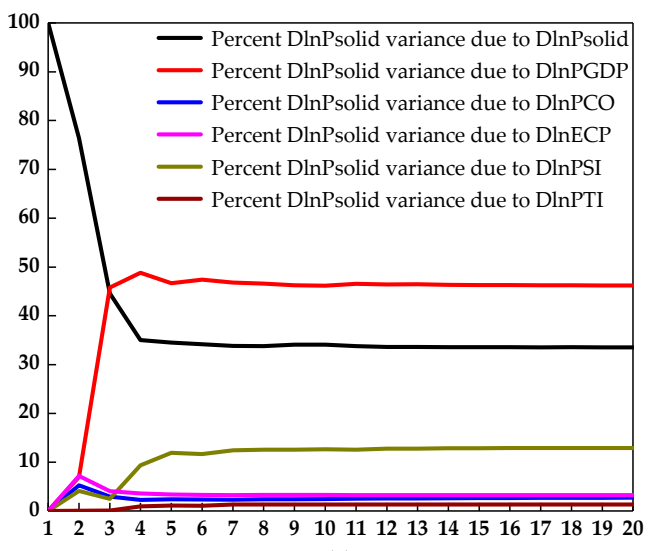

(a)

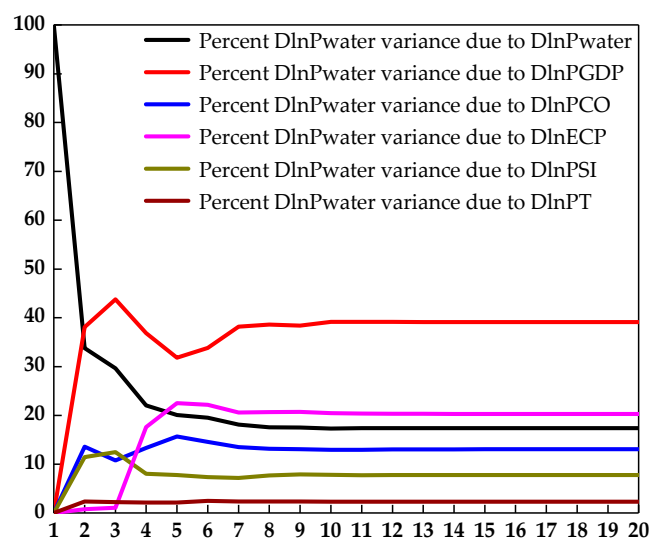

(b)

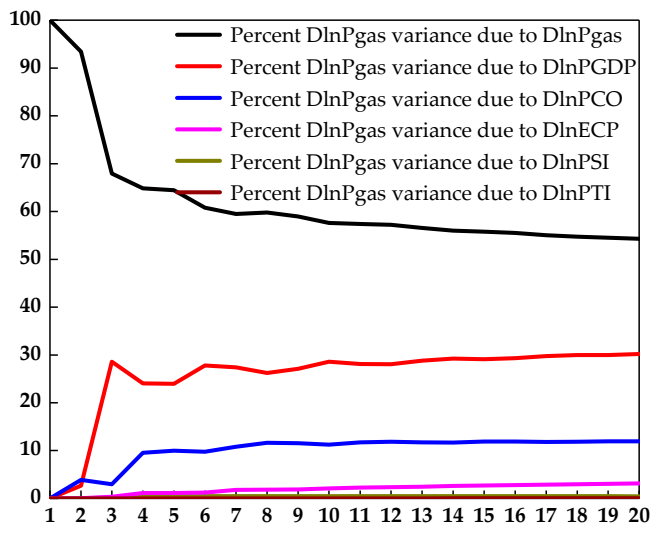

(c)

Figure 4. The variance decomposition of industrial "three wastes" emissions. (a) The result of variance decomposition of DlnPsolid. (b) The result of variance decomposition of DlnPwater. (c) The result of variance decomposition of DlnPgas.

As shown in Figure 4a, DlnPoslid is most affected by itself before the third period, and the contribution of each variable has gradually stabilized since the fourth period. Among them, the change of economic income is the primary reason $(47 \%)$ for the variety of industrial solid waste output, followed by its own impact (33\%). The influence of the proportion of secondary industry accounts for only $12 \%$. The contribution of the remaining three socioeconomic factors is less than $7 \%$, indicating that they are not the main reason for the change of per capita industrial solid waste production in Yulin. Controlling economic growth is the most effective way to reduce the industrial solid waste production according to the variance decomposition curve. However, Yulin City is still in the developing stage. 
Measures still need to start with industrial solid waste itself to relieve the burden on environmental pollution, because it is difficult to improve environmental quality by slow economic growth. Therefore, combined with the primary source of industrial solid waste in Yulin, coal gangue, fly ash, and slag can be used in cement preparation and construction material production to turn waste into treasure, and optimize the industrial structure by increasing the investment and policy support for the tertiary industry. Industrial solid waste production is reduced as much as possible while the economy is steadily growing.

As shown in Figure 4b, the impact of the factors on DlnPwater tends to be stable after the seventh period. Economic income remains the leading reason (39\%) for the variation in industrial wastewater discharge. The energy utilization efficiency will also lead to significant changes $(20 \%)$ in industrial wastewater discharge. Unlike industrial solid waste, industrial wastewater discharge is less affected by itself $(17 \%)$. The raw coal output does influence $(13 \%)$ the industrial wastewater discharge. The remaining two factors have little effect on DlnPwater. Theoretically, economic growth needs to be slowed to reduce the discharge of industrial wastewater. However, the environmental quality can be improved by reducing energy consumption per unit of GDP on the actual situation in Yulin City. Moreover, the generation and discharge of industrial wastewater can also be effectively reduced by popularizing the mine water circulation system and improving purification efficiency.

As shown in Figure 4c, and different from the other two industrial wastes, the change of industrial waste gas emissions is most affected by itself and the proportion exceeds $55 \%$. The contribution of economic income and raw coal output is about $28 \%$ and $9 \%$, respectively. The other three factors account for only about $8 \%$ of the variation of industrial waste gas emissions. The main measures to reduce the emission of industrial waste gas still have to start from itself. In addition to using traditional physical and chemical means to reduce the emissions, the desulfurization process can be popularized to reduce the generation of sulfur dioxide in coal combustion.

\section{Conclusions and Policy Recommendations}

\subsection{Conclusions}

This paper takes Yulin City as an example, and selects GDP per capita, per capita raw coal output, energy consumption per unit of GDP, secondary industrial proportion, and technology investment proportion as indicators that reflect socioeconomic development. The per capita industrial "three wastes" emission represents the degree of environmental pollution. This paper explores the environmental sustainability of coal cities based on the Tapio decoupling model, the EKC hypothesis, and the VAR model, and lays a foundation for the follow-up research on the all-side sustainable development of coal cities.

Through the Tapio decoupling model, we found that the decoupling state between economic growth and environmental degradation has been dominated by expansive negative decoupling in the past two decades of development in Yulin City. Among them, economic growth is more tightly coupled with industrial solid waste production and industrial wastewater discharge. We also found that most of the decoupling elastic index between economic growth and industrial "three wastes" emissions were higher than 1.2 after dividing the study period into three stages. These show that the extensive economic growth pattern has dominated the development of Yulin City, and economic growth will not decouple from the environmental pollution in the short term.

On the EKC model, the per capita GDP exhibited an inverted U-shaped nexus with per capita industrial solid waste production, which is in line with the EKC hypothesis, and the per capita GDP corresponding to the inflection point is 27,511 yuan (in constant $1996 \mathrm{RMB}$ yuan). It is predicted that the industrial solid waste production will reach the peak in 2021 according to the GDP growth rate of Yulin in 2017. There is a U-shaped nexus between per capita GDP and per capita industrial wastewater discharge, and it has already exceeded the inflection point. The nexus between per capita GDP and per capita industrial waste gas emissions is inverted U-shaped in theory, and the per capita GDP 
corresponding to the inflection point is 3.68 million yuan. For the practical situation, however, such a high inflection point indicates that there does not exist the environmental Kuznets curve of per capita industrial waste gas emissions in Yulin City. The economic growth will promote industrial wastewater discharge and industrial waste gas emissions in the coming period.

This paper established three VAR (2) models based on time series data of socioeconomic factors and industrial "three wastes" emissions. The results of the impulse response function show that industrial solid waste production will increase first and then decrease if the economy keeps growing. Moreover, the discharge of industrial wastewater and the emissions of industrial waste gas will keep increasing with economic growth. Moreover, in the long run, the increase in per capita raw coal output, energy consumption per unit of GDP, and proportion of secondary industries will promote the industrial "three wastes" emissions. The increase in technology investment proportion will lead to the fluctuation of industrial "three wastes" emissions. According to the results of the variance decomposition, the change in industrial solid waste production is mainly caused by per capita GDP $(47 \%)$, previous output $(33 \%)$, and industrial structure (12\%). The change in industrial wastewater discharge is impacted by per capita GDP (39\%), energy consumption per unit of GDP $(20 \%)$, and itself $(13 \%)$. The most significant influence on the change in industrial waste gas emissions is its own emissions (55\%), followed by per capita GDP $(28 \%)$ and coal mining $(9 \%)$.

\subsection{Policy Recommendations}

On the basis of the above conclusions, it is necessary to formulate targeted measures from industrial restructuring, industrial chain extension, governance model optimization, and waste comprehensive utilization to realize the environmentally sustainable development of coal cities.

First, as a typical coal city, Yulin has a large proportion of secondary industry in economic development, especially the coal industry. The coal industry belongs to the industrial sector with high consumption, high pollution, and low efficiency, which has the characteristics of low value-added products and low technology correlation. Excessive dependence on the coal industry will inevitably make it difficult for economic growth to decouple from the extensive development pattern. In future economic development, Yulin City should gradually change its development ideas, optimize and adjust the industrial structure, and reduce its dependence on the coal industry, encouraging and supporting the development of the tertiary industry with low energy consumption and high value-added. The government should raise the access threshold for the energy industry and increase the efforts to phase out outdated production capacity to avoid extensive energy development.

Second, in addition to adjusting the industrial structure, Yulin City should also extend the coal resource industry chain to break the shackles of producing only raw coal, expanding the industrial chain from producing only primary coal products to providing a variety of high-quality energy and chemical raw materials. Yunlin should take the new industrialization path of high technological content, high economic benefits, low resource consumption, and less environmental pollution in future development. Furthermore, it should strengthen the comprehensive development and deep processing of coal resources, implement technological improvements and innovations, increase technological content and economic benefits, reduce energy consumption and environmental pollution, and realize the decoupling of economic growth and environmental pollution at an early date.

Third, the government should carry out the accountability system and strictly implement the policy of "who pollutes, governs, who governs and benefits". Environmental taxes are levied according to the type, hazards, and amount of industrial waste. The taxes on companies that actively adopt environmental protection measures should be reduced. Enterprises should promote green design, build green factories and mines, and develop green industrial parks. The industrial wastewater treatment model should be transformed from the mixed collection and centralized treatment to the classified collection and separate treatment. In the treatment of industrial waste gas, besides the traditional absorption method and catalytic combustion method, the biological purification method with high efficiency, low cost, and simple equipment should be promoted, such as biofilter and 
bioscrubbing. The terminal treatment can reduce the damage of industrial "three wastes" emissions to the environment.

Last, but not least, combined with the primary source of industrial solid waste in Yulin City, coal gangue, fly ash, and slag can be used in cement preparation and construction material production in the future environmental treatment. Coal gangue can also be used for mine goaf backfill, and fly ash can be used for the adsorption treatment of petroleum, $\mathrm{COD}$ (Chemical oxygen demand), and nitrogen oxides in industrial wastewater. The industrial wastewater recycling system should be built to promote industrial wastewater recycling use in the manufacturing process, manufacturing plant, and between industries to improve its utilization rate. There are many coal mines in the Yulin region, and coal spontaneous combustion disasters occur frequently. $\mathrm{CO}_{2}$ in the industrial waste gas can be recovered by the physical adsorption method and chemical adsorption method and used for preventing coal spontaneous combustion. Through comprehensive utilization of industrial "three wastes", a sustainable development model of resources-products-waste-recyclable resources can be realized.

Although this study investigates the environmental sustainability of Yulin City by the Tapio decoupling model, the EKC hypothesis, and the VAR model, there are still some limitations, which should be future research directions. First of all, the sustainable development of coal cities is of great significance to the development of China. Moreover, sustainable development is a broad concept, including social sustainable development, economic sustainable development, and environmentally sustainable development. Therefore, we can try to establish a sustainable development model with social, economic, and environmental indicators in the follow-up research. Besides, more coal cities should be selected as research objects, and time series data and panel data should be used to conduct further research on all-sides sustainable development of coal cities, in order to make more reasonable policies.

Author Contributions: Conceptualization, X.Z. and Z.C.; methodology, Z.C.; software, K.A. and B.S.; validation, X.Z. and K.A.; data curation, K.A. and B.S.; writing-original draft preparation, X.Z. and Z.C.; writing-review and editing, X.Z. and Z.C. All authors have read and agreed to the published version of the manuscript.

Funding: This research was funded by National Natural Science Foundation of China (51974236), Key R \& D Project in Shaanxi Province (2018KW-035).

Acknowledgments: We are grateful to the anonymous referees for their comments and suggestions, which significantly improved this paper. We are also indebted to advice from scientific committee members and participants in the 6th International Conference on Energy and Environment Research (ICEER 2019).

Conflicts of Interest: The authors declare no conflict of interest.

\section{Appendix A}

Table A1. The results of the Johansen cointegration test.

\begin{tabular}{ccccc}
\hline EKC Model & Hypothesized No. of CE(s) & Eigenvalue & Trace Statistic & 5\% Critical Value \\
\hline \multirow{3}{*}{ Equation (2) } & None * & 0.917 & 79.231 & 29.797 \\
& Atmost1 * & 0.783 & 31.832 & 15.495 \\
& Atmost2 & 0.138 & 2.811 & 3.841 \\
Equation (3) & None * & 0.746 & 51.241 & 29.797 \\
& Atmost1 * & 0.605 & 23.847 & 15.495 \\
Equation (4) & Atmost2 * & 0.231 & 5.248 & 3.841 \\
& None * & 0.836 & 59.691 & 29.797 \\
& Atmost1 * & 0.647 & 25.344 & 15.495 \\
\hline
\end{tabular}

Notes: * denotes rejection of the hypothesis at the $5 \%$ level. 
Table A2. The results of optimum lag order.

\begin{tabular}{cccccccc}
\hline VAR Model & Lag & LogL & LR & FPE & AIC & SC & HQ \\
\hline \multirow{3}{*}{ DlnPsolid } & 0 & 57.109 & NA & $1.86 \times 10^{-10}$ & -5.380 & -5.082 & -5.330 \\
& 1 & 117.325 & 76.063 & $1.80 \times 10^{-11}$ & -7.929 & -5.841 & -7.576 \\
& 2 & 220.616 & $65.237^{*}$ & $7.61 \times 10^{-14 *}$ & $-15.012 *$ & $-11.135^{*}$ & $-14.356^{*}$ \\
DlnPwater & 0 & 57.109 & NA & $1.86 \times 10^{-10}$ & -5.380 & -5.082 & -5.329 \\
& 1 & 117.325 & 76.063 & $1.80 \times 10^{-11}$ & -7.929 & -5.841 & -7.576 \\
& 2 & 220.616 & $65.238^{*}$ & $7.61 \times 10^{-14 *}$ & $-15.012 *$ & $-11.135 *$ & $-14.356^{*}$ \\
DlnPgas & 0 & 72.269 & NA & $3.77 \times 10^{-11}$ & -6.976 & -6.677 & -6.925 \\
& 1 & 139.297 & 84.667 & $1.79 \times 10^{-12}$ & -10.242 & -8.154 & -9.888 \\
& 2 & 286.519 & $92.982 *$ & $7.39 \times 10^{-17 *}$ & $-21.949 *$ & $-18.072 *$ & $-21.293^{*}$ \\
\hline
\end{tabular}

Notes: * illustrates the optimal lag length order chosen by the criterions.

Table A3. The results of the Johansen cointegration test.

\begin{tabular}{ccccc}
\hline VAR Model & Hypothesized No. of CE(s) & Eigenvalue & Trace Statistic & 5\% Critical Value \\
\hline \multirow{3}{*}{ DlnPsolid } & None * & 0.877 & 67.376 & 29.797 \\
& Atmost1 * & 0.554 & 25.390 & 15.495 \\
\multirow{2}{*}{ DlnPwater } & Atmost2 * & 0.370 & 9.235 & 3.841 \\
& None * $^{*}$ & 0.746 & 51.241 & 29.797 \\
DlnPgas & Atmost1 & 0.605 & 23.847 & 15.495 \\
& Atmost2 * & 0.231 & 5.248 & 3.841 \\
& None * $^{*}$ & 0.802 & 63.610 & 29.797 \\
& Atmost1 * & 0.666 & 31.259 & 15.495 \\
\hline
\end{tabular}

Notes: ${ }^{*}$ denotes rejection of the hypothesis at the $5 \%$ level.

\section{Appendix B. The VAR (2) Model}

$$
\begin{aligned}
& {\left[\begin{array}{c}
\text { DlnPsolid }_{t} \\
\text { DlnPGDP }_{t} \\
\text { DlnPCO }_{t} \\
\text { DlnECP }_{t} \\
\text { DlnPSI }_{t} \\
\text { DlnPTI }_{t}
\end{array}\right]=\left[\begin{array}{r}
0.525 \\
-0.011 \\
-0.275 \\
0.154 \\
0.052 \\
-0.665
\end{array}\right]+\left[\begin{array}{rrrrrr}
-0.272 & -3.421 & 0.543 & 2.277 & 2.651 & 0.068 \\
0.024 & -0.251 & 0.254 & -0.426 & 0.130 & -0.128 \\
0.097 & -1.859 & 0.673 & -1.524 & 1.456 & -0.350 \\
-0.317 & -0.091 & 0.591 & 0.546 & -0.061 & -0.179 \\
-0.012 & 0.029 & 0.026 & -0.172 & -0.187 & 0.076 \\
0.066 & 1.614 & -0.102 & -0.183 & -0.435 & -0.656
\end{array}\right]\left[\begin{array}{c}
\text { DlnPsolid }_{t-1} \\
\text { DlnPGDP }_{t-1} \\
\text { DlnPCO }_{t-1} \\
\text { DlnECP }_{t-1} \\
\text { DlnPSI }_{t-1} \\
\text { DlnPTI }_{t-1}
\end{array}\right]} \\
& +\left[\begin{array}{rrrrrr}
0.072 & 0.642 & -0.312 & -0.306 & 1.101 & 0.147 \\
0.054 & 0.608 & 0.255 & 0.306 & -0.224 & -0.128 \\
0.084 & 3.887 & 0.184 & 0.498 & -1.346 & -0.677 \\
-0.097 & -1.167 & 0.029 & 0.658 & 0.436 & -0.024 \\
0.022 & -0.901 & 0.318 & 0.121 & 0.517 & 0.030 \\
-0.020 & 3.841 & -0.381 & -1.041 & -1.734 & -0.320
\end{array}\right]\left[\begin{array}{c}
\text { DlnPsolid }_{t-2} \\
\text { DlnPGDP }_{t-2} \\
\text { DlnPCO }_{t-2} \\
\text { DlnECP }_{t-2} \\
\text { DlnPSI }_{t-2} \\
\text { DlnPTI }_{t-2}
\end{array}\right]
\end{aligned}
$$




$$
\begin{aligned}
& {\left[\begin{array}{c}
\text { DlnPwater }_{\mathrm{t}} \\
\text { DlnPGDP }_{\mathrm{t}} \\
\text { DlnPCO }_{\mathrm{t}} \\
\text { DlnECP }_{\mathrm{t}} \\
\text { DlnPSI }_{\mathrm{t}} \\
\text { DlnPTI }_{\mathrm{t}}
\end{array}\right]=\left[\begin{array}{r}
0.470 \\
0.052 \\
0.053 \\
-0.114 \\
0.019 \\
0.112
\end{array}\right]+\left[\begin{array}{rrrrrr}
-0.618 & -0.425 & 0.537 & 2.028 & 1.808 & 0.616 \\
0.090 & -0.452 & 0.227 & -0.207 & 0.539 & -0.023 \\
0.391 & -4.526 & 1.064 & -0.535 & 3.322 & -0.146 \\
-0.045 & 0.414 & 0.654 & 0.324 & -0.214 & -0.358 \\
-0.025 & 0.512 & -0.090 & -0.234 & -0.311 & 0.108 \\
0.432 & -3.426 & 0.795 & 0.791 & 1.289 & -0.567
\end{array}\right]\left[\begin{array}{c}
\text { DlnPwater }_{\mathrm{t}-1} \\
\text { DlnPGDP }_{\mathrm{t}-1} \\
\text { DlnPCO }_{\mathrm{t}-1} \\
\operatorname{DlnECP}_{\mathrm{t}-1} \\
\text { DlnPSI }_{\mathrm{t}-1} \\
\text { DlnPTI }_{\mathrm{t}-1}
\end{array}\right]} \\
& +\left[\begin{array}{rrrrrr}
-0.074 & 0.135 & -1.479 & -0.432 & -1.626 & 1.040 \\
0.043 & 0.471 & 0.080 & 0.187 & -0.078 & -0.066 \\
0.350 & 3.639 & -0.416 & 0.278 & -0.386 & -0.521 \\
-0.064 & 0.104 & -0.063 & 0.303 & -0.905 & -0.183 \\
-0.048 & -0.919 & 0.316 & 0.063 & 0.381 & 0.043 \\
0.502 & 1.621 & -0.276 & 0.095 & 1.662 & -0.241
\end{array}\right]\left[\begin{array}{c}
\text { DlnPwater }_{t-2} \\
\text { DlnPGDP }_{t-2} \\
\text { DlnPCO }_{t-2} \\
\text { DlnECP }_{t-2} \\
\text { DlnPSI }_{t-2} \\
\text { DlnPTI }_{t-2}
\end{array}\right]
\end{aligned}
$$

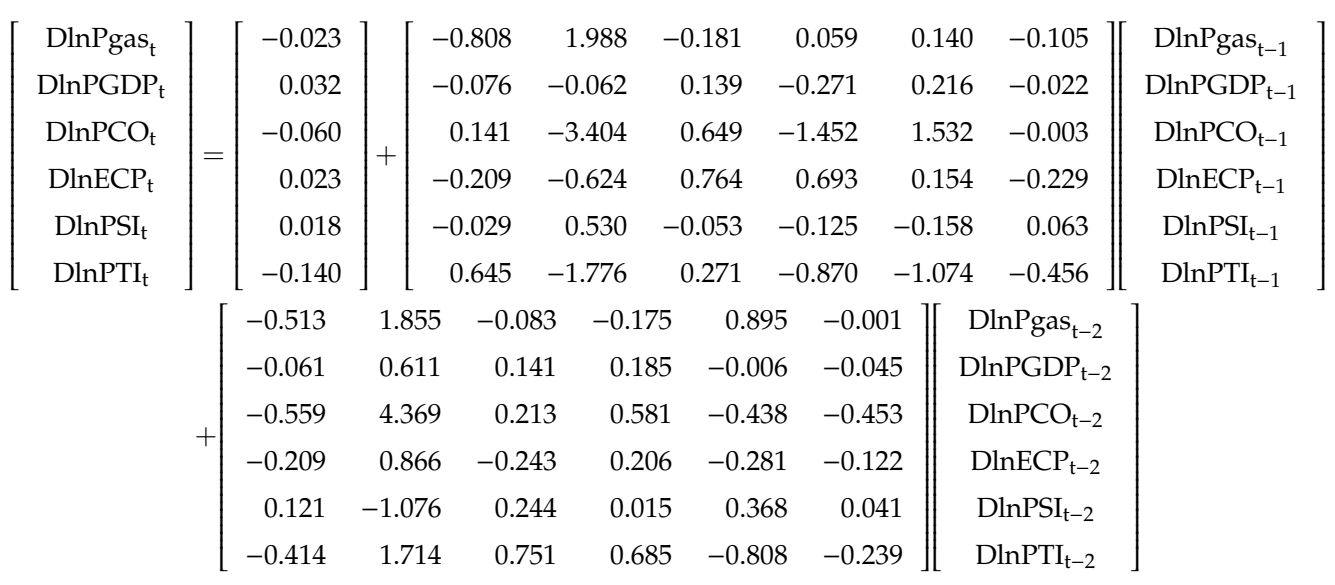

\section{References}

1. Solarin, S.A.; Shahbaz, M.; Hammoudeh, S. Sustainable economic development in China: Modelling the role of hydroelectricity consumption in a multivariate framework. Energy 2019, 168, 516-531. [CrossRef]

2. China Statistical Yearbook. Available online: http://www.stats.gov.cn/tjsj/ndsj/2019/indexch.htm (accessed on 24 September 2019).

3. BP Statistical Review of World Energy 2019. Available online: https://www.bp.com/content/dam/bp/businesssites/en/global/corporate/pdfs/energy-economics/statistical-review/bp-stats-review-2019-full-report.pdf (accessed on 19 June 2019).

4. Hou, Y.L.; Long, R.Y.; Chen, H.; Zhang, L.L. Research on the sustainable development of China's coal cities based on lock-in effect. Resour. Policy 2018, 59, 479-486. [CrossRef]

5. Song, M.L.; Wang, J.L.; Zhao, J.J. Coal endowment, resource curse, and high coal-consuming industries location: Analysis based on large-scale data. Resour. Conserv. Recycl. 2018, 129, 333-344. [CrossRef]

6. Peng, K.; Cheng, R.H.; Cheng, G. An application of system dynamics for evaluating planning alternatives to guide a green industrial transformation in a resource-based city. J. Clean. Prod. 2015, 104, 403-412.

7. Choi, J.K.; Kim, K.D.; Lee, S.; Won, J.S. Application of a fuzzy operator to susceptibility estimations of coal mine subsidence in Taebaek City, Korea. Environ. Earth Sci. 2010, 59, 1009-1022. [CrossRef]

8. Zeng, L.J.; Guo, J.Q.; Wang, B.C.; Lv, J.; Wang, Q. Analyzing sustainability of Chinese coal cities using a decision tree modeling approach. Resour. Policy 2019, 64, 101501. [CrossRef]

9. Zhai, X.W.; Cheng, Z.; Chang, S.H.; Ai, X.F.; Zhang, X.Z. An analysis on the current situation of energy development and its environmental problems in Yulin City. Energy Rep. 2020, 6, 15-20. [CrossRef]

10. Zhou, X.P.; Lu, X.L.; Lian, H.P.; Chen, Y.C.; Wu, Y.Q. Construction of a Spatial Planning system at city-level: Case study of "integration of multi-planning" in Yulin City, China. Habitat Int. 2017, 65, 32-48. [CrossRef] 
11. Zhu, Y.; Tong, Q.L.; Yan, X.X.; Li, Y.X. Development of an uncertain Gaussian diffusion model with its application to production-emission system management in coal-dependent city- a case study of Yulin, China. Energy Proc. 2019, 158, 3253-3258. [CrossRef]

12. Statistical Report of National Economic and Social Development of Yulin City. Available online: http: //tjj.yl.gov.cn/9/17/list.aspx (accessed on 2 April 2019).

13. Liu, J.; Liu, Y.; Liu, Y.J.; Liu, Z.; Zhang, A.N. Quantitative contributions of the major sources of heavy metals in soils to ecosystem and human health risks: A case study of Yulin, China. Ecotox. Environ. Saf. 2018, 164, 261-269. [CrossRef]

14. Zhou, M.; Li, X.P.; Zhang, M.; Liu, B.; Zhang, Y.C.; Gao, Y.; Ullah, H.; Peng, L.Y.; He, A.; Yu, H.T. Water quality in a worldwide coal mining city: A scenario in water chemistry and health risks exploration. J. Geochem. Explor. 2020, 213, 106531. [CrossRef]

15. Dong, D.L.; Wu, Q.; Zhang, R.; Song, Y.X.; Chen, S.K.; Li, P.; Liu, S.Q.; Bi, C.C.; Lv, Z.Q.; Huang, S.L. Environmental Characteristics of Groundwater: An Application of PCA to Water Chemistry Analysis in Yulin. J. Chin. Univ. Min. Technol. 2007, 17, 73-77. [CrossRef]

16. Lei, Y.L.; Shen, Z.X.; Wang, Q.Y.; Zhang, T.; Cao, J.J.; Sun, J.; Zhang, Q.; Wang, L.Q.; Xu, H.M.; Tian, J.; et al. Optical characteristics and source apportionment of brown carbon in winter $\mathrm{PM}_{2.5}$ over Yulin in Northern China. Atmos. Res. 2018, 213, 27-33. [CrossRef]

17. Kuznets, S. Economic growth and income inequality. Am. Econ. Rev. 1955, 45, 1-28.

18. Grossman, G.M.; Krueger, A.B. Environmental Impacts of a North American Free Trade Agreement; National Bureau of Economics-NBER: Cambridge, UK, 1991.

19. Arrow, K.; Bolin, B.; Costanza, R.; Dasgupta, P.; Folke, C.; Holling, C.S.; Jansson, B.; Levin, S.; Maler, K.; Perrings, C.; et al. Economic growth, carrying capacity, and the environment. Science 1995, 268, 520-521. [CrossRef]

20. List, J.A.; Gallet, C.A. The environmental Kuznets curve: Does one size fit all? Ecol. Econ. 1999, 31, 409-423. [CrossRef]

21. Liu, X.Z.; Heilig, G.K.; Chen, J.M.; Heino, M. Interactions between economic growth and environmental quality in Shenzhen, China's first special economic zone. Ecol. Econ. 2007, 62, 559-570. [CrossRef]

22. Katircioğlu, S.T. Testing the tourism-induced EKC hypothesis: The case of Singapore. Econ. Model. 2014, 41, 383-391. [CrossRef]

23. Bimonte, S.; Stabile, A. Land consumption and income in Italy: A case of inverted EKC. Ecol. Econ. 2017, 131, 36-43. [CrossRef]

24. Sinha, A.; Shahbaz, M. Estimation of Environmental Kuznets Curve for $\mathrm{CO}_{2}$ emission: Role of renewable energy generation in India. Renew. Energy 2018, 119, 703-711. [CrossRef]

25. Lin, B.Q.; Omoju, O.E.; Nwakeze, N.M.; Okonkwo, J.U.; Megbowon, E.T. Is the environmental Kuznets curve hypothesis a sound basis for environmental policy in Africa? J. Clean. Prod. 2016, 133, 712-724. [CrossRef]

26. Fujii, H.; Managi, S. Which industry is greener? An empirical study of nine industries in OECD countries. Energy Policy 2013, 57, 381-388. [CrossRef]

27. Zhao, H.R.; Guo, S.; Zhao, H.R. Characterizing the influences of economic development, energy consumption, urbanization, industrialization, and vehicles amount on $\mathrm{PM}_{2.5}$ concentrations of China. Sustainability 2018, 10, 2574. [CrossRef]

28. He, L.J.; Liu, Y.; He, P.P.; Zhou, H. Relationship between air pollution and urban forms: Evidence from prefecture-level cities of the Yangtze River Basin. Int. J. Environ. Health Res. 2019, 16, 3459. [CrossRef] [PubMed]

29. Shujahat, H.S.; Fan, H.Z.; Zeeshan, F.; Roksana, B. Testing non-linear nexus between service sector and $\mathrm{CO}_{2}$ emissions in Pakistan. Energies 2020, 13, 526.

30. Urban, F.; Nordensvärd, J. Low carbon energy transitions in the Nordic countries: Evidence from the environmental Kuznets curve. Energies 2018, 11, 2209. [CrossRef]

31. Pata, U.K. Renewable energy consumption, urbanization, financial development, income and $\mathrm{CO}_{2}$ emissions in Turkey: Testing EKC hypothesis with structural breaks. J. Clean. Prod. 2018, 187, 770-779. [CrossRef]

32. Pao, H.P.; Chen, C.C. Decoupling strategies: $\mathrm{CO}_{2}$ emissions, energy resources, and economic growth in the Group of Twenty. J. Clean. Prod. 2019, 206, 907-919. [CrossRef]

33. Stern, D.I. The rise and fall of the environmental Kuznets curve. World Dev. 2004, 32, 1419-1439. [CrossRef] 
34. Carson, R. The environmental Kuznets curve: Seeking empirical regularity and theoretical structure. Rev. Environ. Econ. Policy 2010, 4, 3-23. [CrossRef]

35. Garter, A. The economics of Technological Change. Sci. Am. 1996, 214, 25-31.

36. Indicators to Measure Decoupling of Environmental Pressure from Economic Growth. Sustainable Development. Available online: http://www.olis.oecd.org/olis/2002doc.nsf/LinkTo/sg-sd(2002)1-final (accessed on 28 August 2010).

37. Vehmas, J.; Malaska, P.; Luukkanen, J.; Kaivo-oja, J.; Hietanen, O.; Vinnari, M.; Ilvonen, J. Europe in the Global Battle of Sustainability: Rebound Strikes Back? Advanced Sustainability Analysis, Publications of the Turku School of Economics and Business Administration: Turku, Finland, 2003.

38. Tapio, P. Towards a theory of decoupling: Degrees of decoupling in the EU and the case of road traffic in Finland between 1970 and 2001. Transp. Policy 2005, 12, 137-151. [CrossRef]

39. Freitas, L.C.; Kaneko, S. Decomposing the decoupling of $\mathrm{CO}_{2}$ emissions and economic growth in Brazil. Ecol. Econ. 2011, 70, 1459-1469. [CrossRef]

40. Wang, Q.; Wang, S.S. A comparison of decomposition the decoupling carbon emissions from economic growth in transport sector of selected provinces in eastern, central and western China. J. Clean. Prod. 2019, 229, 570-581. [CrossRef]

41. Gou, W.B.; Chen, Y. Assessing the efficiency of China's environmental regulation on carbon emissions based on Tapio decoupling models and GMM models. Energy Rep. 2018, 4, 713-723.

42. Zhou, X.; Zhang, M.; Zhou, M.H.; Zhou, M. A comparative study on decoupling relationship and influence factors between China's regional economic development and industrial energy-related carbon emissions. J. Clean. Prod. 2017, 142, 783-800. [CrossRef]

43. Wu, Y.; Tam, V.W.Y.; Shuai, C.Y.; Shen, L.Y.; Zhang, Y.; Liao, S.J. Decoupling China's economic growth from carbon emissions: Empirical studies from 30 Chinese provinces (2001-2015). Sci. Total Environ. 2019, 656, 576-588. [CrossRef]

44. Jiang, J.J.; Ye, B.; Zhou, N.; Zhang, X.L. Decoupling analysis and environmental Kuznets curve modelling of provincial-level $\mathrm{CO}_{2}$ emissions and economic growth in China: A case study. J. Clean. Prod. 2019, 212, 1242-1255. [CrossRef]

45. Statistical Yearbook of Yulin. Available online: http://tjj.yl.gov.cn/9/17/list.aspx (accessed on 2 April 2019).

46. Statistical Yearbook of Shaanxi. Available online: http://tj.shaanxi.gov.cn/site/1/html/126/127/233/list.htm (accessed on 11 November 2018).

47. Wang, Y.H.; Xie, T.Y.; Yang, S.L. Carbon emission and its decoupling research of transportation in Jiangsu Province. J. Clean. Prod. 2017, 142, 907-914. [CrossRef]

48. Feng, J.C.; Zeng, X.L.; Yu, Z.; Bian, Y.; Li, W.C.; Wang, Y. Decoupling and driving forces of industrial carbon emission in a coastal city of Zhuhai, China. Energy Rep. 2019, 5, 1589-1602. [CrossRef]

49. Bimonte, S.; Stabile, A. EKC and the income elasticity hypothesis Land for housing or land for future? Ecol. Indic. 2017, 73, 800-808. [CrossRef]

50. Baek, J. Environmental Kuznets curve for $\mathrm{CO}_{2}$ emissions: The case of Arctic countries. Energy Econ. 2015, 50, 13-17. [CrossRef]

51. Alter, A.; Schuler, Y.S. Credit spread interdependencies of european states and banks during the financial crisis. J. Bank Financ. 2012, 36, 3444-3468. [CrossRef]

52. Bratis, T.; Laopodis, N.T.; Kouretas, G.P. Contagion and interdependence in eurozone bank and sovereign credit markets. Int. J. Financ. Econ. 2018, 23, 655-674. [CrossRef]

53. Annual Solid Waste Pollution Prevention Information of Yulin City. Available online: http://hb.yl.gov.cn/ show.jsp?article_id=224bb01c0ce749abbda836f57bcfad93 (accessed on 4 June 2019).

54. Wu, Y.Y.; Zhu, X.W.; Groenewold, N. The determinants and effectiveness of industrial policy in china: A study based on Five-Year Plans. China Econ. Rev. 2019, 53, 225-242. [CrossRef]

55. Dickey, D.A.; Fuller, W.A. Likelihood ratio statistics for autoregressive time series with a unit root. Econometrica 1981, 49, 1057-1072. [CrossRef]

56. Phillips, P.C.; Perron, P. Testing for a unit root in time series regression. Biometrika 1988, 75, 335-346. [CrossRef]

57. Johansen, S.; Juselius, K. Maximum likelihood estimation and inference on cointegration-with application to the demand for money. Oxf. Bull. Econ. Stat. 1990, 52, 169-210. [CrossRef] 
58. Statistical Bulletin of National Economic and Social Development of Yulin City. Available online: http: //www.yl.gov.cn/P/C/35692.htm (accessed on 2 April 2018).

59. Shi, A.Q. The impact of population pressure on global carbon dioxide emissions, 1975-1996: Evidence from pooled cross-country data. Ecol. Econ. 2003, 44, 29-42. [CrossRef]

60. Holtz-Eakin, D.; Selden, T.M. Stoking the fires? $\mathrm{CO}_{2}$ emissions and economic growth. J. Public Econ. 1995, 57, 85-101. [CrossRef]

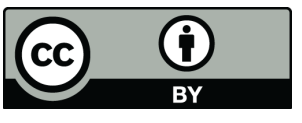

(C) 2020 by the authors. Licensee MDPI, Basel, Switzerland. This article is an open access article distributed under the terms and conditions of the Creative Commons Attribution (CC BY) license (http://creativecommons.org/licenses/by/4.0/). 